\title{
Carlos Ercoli, figura clave de la pintura abstracta argentina
}

La obra pictórica del mendocino Carlos Ercoli (1940) se inscribe entre las cumbres del arte abstracto argentino, uno de cuyos representantes fue Emilio Pettoruti (1892-1871). En un principio manifestó inclinación por la medicina y, en 1957, se trasladó a Córdoba e inició sus estudios fuertemente atraído por la vida celular, microscópica, ese mundo físico constitutivo pero imperceptible a simple vista. De haber sido médico -sostiene-, se habría dedicado a la investigación de esos microcosmos biológicos. Pero no lo fue. Y es que esos mundos infinitamente pequeños no lograron sustraerlo al enfrentamiento con el dolor humano al que inevitablemente lo ligaría esa profesión. Por lo tanto, abandonó esa carrera profesional y se introdujo en la efervescencia de esa suerte de rebelión contra la muerte que es el arte. Quizás exista una analogía entre el interés de Ercoli por la medicina y su definitiva vocación por las artes. Así como de la medicina le atraía el mundo microscópico de la biología humana, el arte prometía la construcción de un espacio imaginario también como un mundo aparte de la cotidianidad. Esa fue la vía por la cual dentro del amplio espectro de las artes se aferró a la abstracción, ya que la representación naturalista y figurativa parecía no dar cuenta de los fundamentos no visibles de aquello que llamamos realidad. Lejos de pensar la abstracción como una forma de evasión, ésta parecía ser la vía para explorar aspectos esenciales de la vida. En sus propias palabras: "todo artista, si lo es realmente, está inmerso en la realidad de su tiempo, y nuestro tiempo es, en buena medida, el tiempo de la física nuclear, del psicoanálisis[...] Una nueva realidad ha surgido tras las apariencias de nuestro mundo 'natural'."

En la ciudad de Córdoba, precisamente, se vinculó a un fuerte proceso de modernización del campo artístico que impulsaba el desarrollo del arte abstracto. A fines de la década de 1950, Córdoba se erigía como uno de los polos del proyecto de internacionalización del arte argentino encabezado en Buenos Aires por Jorge Romero Brest desde el Instituto Torcuato Di Tella, y por Rafael Squirru desde el Museo de Arte Moderno de Buenos Aires. Los salones IKA y las Bienales Americanas de Arte fueron las vías de acceso al arte moderno del resto del mundo y el canal de circulación de las propuestas más avanzadas. A su regreso a Mendoza en 1964, Ércoli fue un reconocido maestro en la Escuela Superior de Bellas Artes.Abandonó los rígidos esquemas figurativos que había asimilado en su infancia y adolescencia, y se volcó al arriesgado arte abstracto. Por cierto, su producción temprana refleja cierta influencia de Paul Klee, aunque la paciente experimentación con el color en su taller perfiló un estilo propio, con cuadros que algunos confundían con el acrílico debido a la limpidez del óleo. Con ello refleja ese mundo invisible que opera como estructura fundamental de lo visible. 
Aun así, el entusiasmo inicial en torno a la abstracción se topó con el límite histórico de sus opuestos. Según Ércoli, el arte no figurativo llegó a considerarse transgresor. Las fuertes resistencias en el medio plástico de la provincia de Mendoza parecían ser un elemento en común entre posiciones ideológicas contrarias. Por un lado, los tradicionalistas asociados con los sectores conservadores provinciales no veían en la abstracción más que una suerte de pérdida de valores esenciales e identitarios que debían ser defendidos frente a lo que postulaban como una disgregación nacional signada por el cosmopolitismo. Apoyaban un arte regional identificado con la figuración, el naturalismo y el paisaje. Por otro lado, los que sostenían la necesidad de politizar a los artistas y el compromiso con los sectores populares para la transformación social observaban con recelo y desconfianza las motivaciones de un movimiento no figurativo al que vinculaban, en el mejor de los casos, con una moda pasajera e insustancial; y en el peor, con un instrumento de "penetración imperialista”. Ambas tendencias, una conservadora y otra revolucionaria, la tensión entre "ser" y "devenir", aunque enfrentadas entre sí, coincidían en su rechazo de un arte abstracto que parecía ser el exponente estético de procesos de modernización impulsados desde el exterior, procesos que mientras para unos significaban el extravío de valores tradicionales, para otros impedían el compromiso con una nueva posible y futura emancipación.

Lic. Pablo Chiavazza (profesor investigador de la UNCuyo) Mendoza, septiembre de 2019 